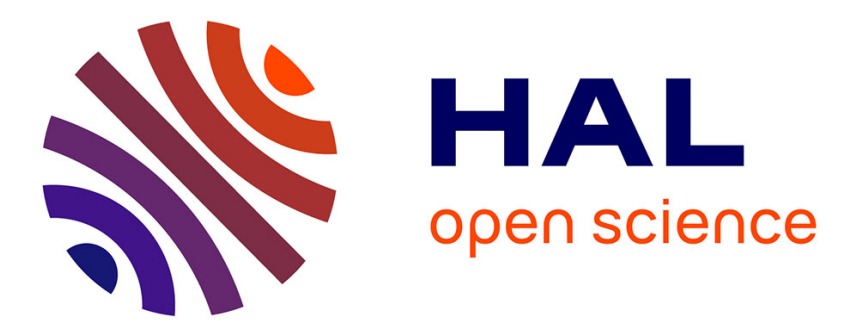

\title{
Analysis and optimization of lateral thin-film silicon-on-insulator (SOI) PMOS transistor with an NBL layer in the drift region
}

Ignasi Cortés, Gaëtan Toulon, Frédéric Morancho, David Flores, Elsa

Hugonnard-Bruyère, Bruno Villard

\section{To cite this version:}

Ignasi Cortés, Gaëtan Toulon, Frédéric Morancho, David Flores, Elsa Hugonnard-Bruyère, et al.. Analysis and optimization of lateral thin-film silicon-on-insulator (SOI) PMOS transistor with an NBL layer in the drift region. Solid-State Electronics, 2012, 70, pp.8-13. 10.1016/j.sse.2011.11.012 . hal-01054152

\section{HAL Id: hal-01054152 \\ https://hal.science/hal-01054152}

Submitted on 5 Aug 2014

HAL is a multi-disciplinary open access archive for the deposit and dissemination of scientific research documents, whether they are published or not. The documents may come from teaching and research institutions in France or abroad, or from public or private research centers.
L'archive ouverte pluridisciplinaire HAL, est destinée au dépôt et à la diffusion de documents scientifiques de niveau recherche, publiés ou non, émanant des établissements d'enseignement et de recherche français ou étrangers, des laboratoires publics ou privés. 


\title{
Analysis and Optimization of Lateral Thin-Film Silicon-on-Insulator (SOI) PMOS Transistor with an NBL layer in the Drift Region
}

\author{
I. Cortés ${ }^{1}$, G. Toulon ${ }^{2,3}$, F. Morancho ${ }^{2,3}$, D. Flores ${ }^{1}$, E. Hugonnard-Bruyère ${ }^{4}$ and B. \\ Villard $^{4}$ \\ ${ }^{1}$ Instituto de Microelectrónica de Barcelona (IMB-CNM) CSIC, Campus UAB, 08193 Bellaterra, \\ Barcelona, Spain \\ ${ }^{2}$ CNRS; LAAS; 7, Avenue du Colonel Roche; F-31077 Toulouse, France \\ ${ }^{3}$ Université de Toulouse; UPS, INSA, INP, ISAE; LAAS; F-31077 Toulouse, France \\ ${ }^{4}$ ATMEL Rousset; Zone Industrielle; 13106 Rousset Cedex, France
}

\begin{abstract}
This paper analyses the experimental results of voltage capability $\left(\mathrm{V}_{\mathrm{BR}}>120 \mathrm{~V}\right)$ and output characteristics of a new lateral power P-channel MOS transistors manufactured on a $0.18 \mu \mathrm{m}$ SOI CMOS technology by means of TCAD numerical simulations. The proposed LDPMOS structure have an N-type buried layer (NBL) inserted in the P-well drift region with the purpose of increasing the RESURF effectiveness and improving the static characteritics $\left(\mathrm{R}_{\mathrm{on}-\mathrm{sp}} / \mathrm{V}_{\mathrm{BR}}\right.$ trade-off) and the device switching performance. Some architecture modifications are also proposed in this paper to further improve the performance of fabricated transitors.
\end{abstract}

\section{Introduction}

Lateral double diffused MOS (LDMOS) transistor is the best suited power switch for integrated circuits thanks to its faster switching time [1] compared to bipolar transistor and its ease of integration with CMOS technology. P-channel LDMOS (LDPMOS) transistors are widely used as high side power devices since it reduces its gate drive circuitry. Associated with the N-channel (LDNMOS) counterpart, they are employed in level shifters in many applications such as motor drivers or display panels. Good specific on-state resistance / breakdown voltage $\left(\mathrm{R}_{\mathrm{on}-\mathrm{sp}} / \mathrm{V}_{\mathrm{BR}}\right)$ trade-off of LDNMOS [2] is possible thanks to the Reduced SURface Field (RESURF) principle, since substrate is grounded and drain forward biased. However, for LDPMOS, this principle is inhibited because drain and substrate are commonly biased to the same potential. Some designs were developed in order to overcome this issue. In Bulk and thick film SOI technology the vertical depletion is possible with the inclusion of N-type floating layers at the surface [3] or deep inside the active Silicon region [4]. The presence of the N-type floating layer associated with a field plate defines the double RESURF [5] which leads to competitive $\mathrm{R}_{\mathrm{on} \text {-sp }} / \mathrm{V}_{\mathrm{BR}}$ trade-off. However, in thin-film SOI, the small active Silicon area reduces the possibility to define an N-type floating region without degrading the device $\mathrm{R}_{\mathrm{on} \text {-sp. }}$. Consequently, only the effect of the field plate is possible and the doping concentration of the drift region which sustains the voltage has to be lowered, leading to an inevitable increase of $\mathrm{R}_{\text {on-sp. }}$. Adopting the fine CMOS process technology to the LDMOS process enables the shrinking of power devices and the possibility to use different design architectures and methodologies, such as the super-junction concept, to improve their switching performance [6]. In this work, the already proposed LDPMOS 
design in thin-SOI technology with a controlled N-type buried layer (NBL) in the drift region obtained by means of high-energy Phosphorus and Boron multi-implantation sequence [6] has been fabricated to improve the $\mathrm{R}_{\mathrm{on}-\mathrm{sp}} / \mathrm{V}_{\mathrm{BR}}$ trade-off of the conventional LDPMOS without any additional CMOS process steps. The experimental results are analysed in this paper, and some possible design modification are proposed by means of TCAD numerical simulations results [7].

\section{LDPMOS structures description}

Fig. 1 shows the schematic cross-section of a conventional LDPMOS and the proposed NBL-LDPMOS transistor, being both structures based upon a $0.18 \mu \mathrm{m}$ smart power technology on thin-SOI substrate with a SOI layer $\left(\mathrm{T}_{\mathrm{SOI}}\right)$ and buried oxide $\left(\mathrm{T}_{\mathrm{BOx}}\right)$ thicknesses of $1.5 \mu \mathrm{m}$ and $1 \mu \mathrm{m}$, respectively. An STI (Shallow Trench Isolation) oxidation is previously defined, partially or totally covering the drift region length ( $\mathrm{L}_{\mathrm{LDD}}$ ). The same $\mathrm{L}_{\mathrm{LDD}}$ of $8 \mu \mathrm{m}$ for a total cell length of $11.5 \mu \mathrm{m}$ is also considered. Other additional common design parameters defined in Fig. 1 are a channel oxide thickness $\left(\mathrm{T}_{\mathrm{ox}}\right)$ of $7 \mathrm{~nm}$, a Poly-gate length not covered by the STI (L $\mathrm{L}_{\text {PolyTox }}$ of $2 \mu \mathrm{m}$ ) and covered by the STI $\left(\Delta \mathrm{L}_{\text {Poly }}\right.$ of $\left.3.5 \mu \mathrm{m}\right)$ and a STI thickness $\left(\mathrm{T}_{\mathrm{STI}}\right)$ of $0.46 \mu \mathrm{m}$. The NBL layer, which is defined with the same P-well mask, could connect to the $\mathrm{N}$-well diffusion, as observed in Fig. $1 \mathrm{~b}$.

The addition of an NBL deep inside the drift region supports a space-charge depletion region which highly increases the RESURF effectiveness, thus improving the $V_{\mathrm{BR}}$. Then, an optimum NBL implanted dose has to be set in order to ensure fully depletion before breakdown, thus achieving the best reliability conditions with a compensated charge balance among $\mathrm{N}$ and $\mathrm{P}$ doping in the drift region. Since the drift depletion action is enhanced with the addition of the NBL layer, the P-well implanted dose can be further increased to maintain charge balance, which could lead to a reduction of the

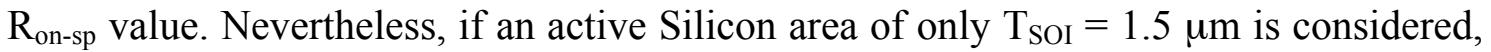
the NBL thickness $\left(\mathrm{T}_{\mathrm{NBL}}\right.$ ) must be as small as possible in order to not excessively reduce the drift current path which could highly penalize the device $\mathrm{R}_{\text {on-sp }}$ value [6]. As it can be inferred from the schematic of Fig. 1b, NBL is depleted by the combined action of substrate field-effect action, and the P-well/NBL junction. Then, the optimal NBL implanted charge must be appropriately chosen to compensate both depletion effects. An extensive comparative analysis of both LDPMOS structure can be found in $[6]$. 


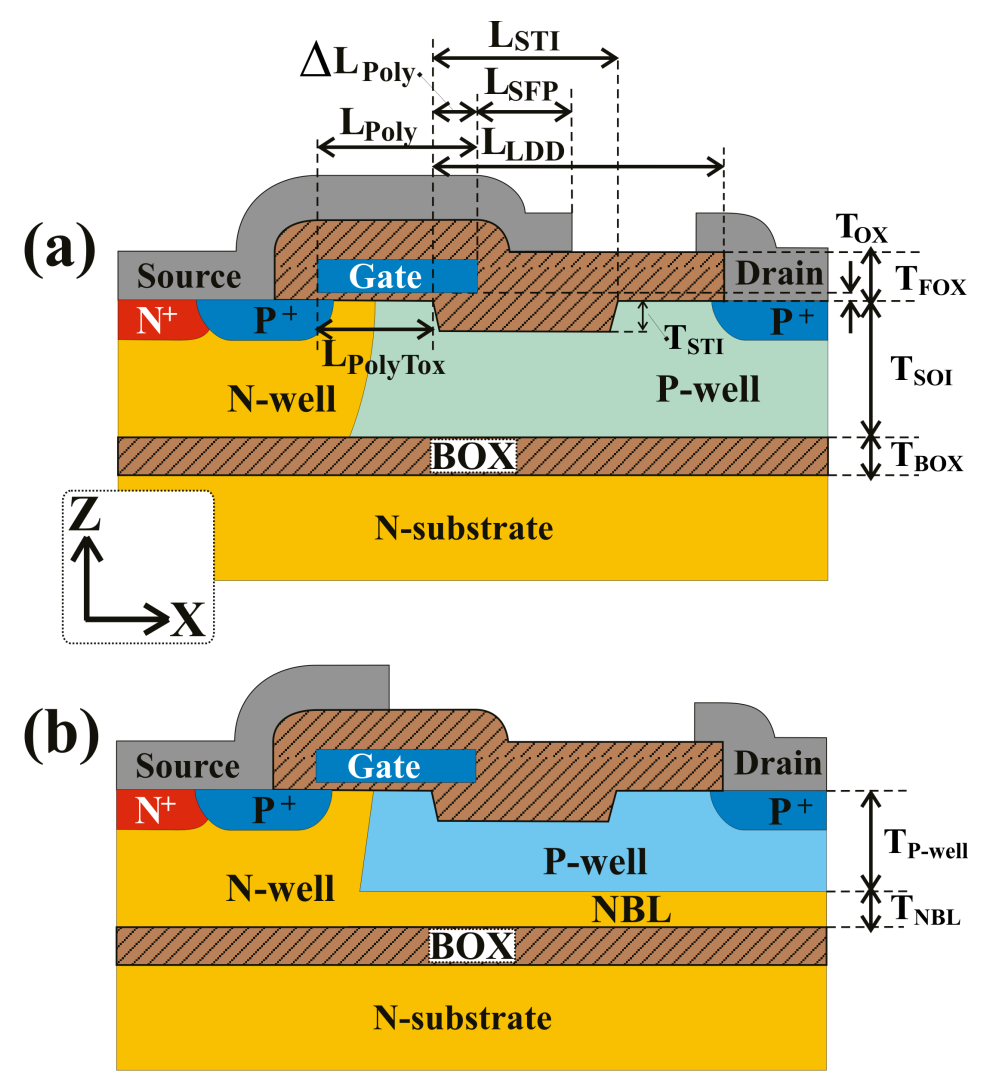

Fig. 1 Schematic cross-section of the (a) conventional LDPMOS and (b) proposed NBL-LDPMOS transistors

\section{Analysis of the experimental results of NBL-LDPMOS}

The complete set of measured electrical characteristics presented in this article are investigated using TCAD tools [7]. Fig. 2 shows the NBL-LDPMOS structure obtained with TCAD technological simulations, by using the same process flow of the fabricated transistors. As observed in Fig. 2, the N-well implantation window is not self-aligned with the Poly at the Source side $(\Delta$ Nwell of $0.75 \mu \mathrm{m})$ and the P-well implantation window is at a certain distance ( $\Delta$ Wells) from the N-well mask. Concretely, two different $\Delta$ Wells values are taken into account: $\Delta$ Wells of $0.75 \mu \mathrm{m}$ and $1.25 \mu \mathrm{m}$. Considering an $\mathrm{L}_{\text {PolyTox }}$ of $2 \mu \mathrm{m}$ (see Fig. 1), a $\Delta$ Wells of $0.75 \mu \mathrm{m}$ leads to a portion of the P-well mask overhanging the Gate region not covered by the STI. As a result, high $\mathrm{BF}_{2}$ concentration is located at the gate oxide surface close to the STI (see Fig. 2a) due to the $\mathrm{BF}_{2}$ low energy implantation used in the threshold voltage $\left(\mathrm{V}_{\mathrm{TH}}\right)$ adjustment in complementary N-channel LDMOS. On the other hand, no presence of surface $\mathrm{BF}_{2}$ concentration is resulted when $\Delta$ Wells is $1.25 \mu \mathrm{m}$ (see Fig. 2b). The resulting net doping profile through the Silicon active area at $X=3.2 \mu \mathrm{m}$ is illustrated in Fig. 3a $(\Delta$ Wells $=0.75 \mu \mathrm{m})$ and Fig. $3 \mathrm{~b}(\Delta \mathrm{Wells}=1.25 \mu \mathrm{m})$. The presence of the Phosphorus queue due to the NBL implantation is also observed in Fig. 3a $(\Delta$ Wells $=0.75 \mu \mathrm{m})$. However, no contact between the N-diffusion and the NBL layer is achieved in any case. The obtained doping profile in the drift region $(X=8 \mu \mathrm{m})$ in Fig. $3 \mathrm{c}$ shows higher Boron effective concentration $\left(Q_{\text {Pwell }}=1.2 \mathrm{e} 12 \mathrm{~cm}^{-2}\right)$ as compared with the Phosphorus effective concentration $\left(Q_{\mathrm{NBL}}=6.2 \mathrm{e} 11 \mathrm{~cm}^{-2}\right)$ of the NBL layer. The RESURF effectiveness analysis of the NBL layer have shown optimal voltage capability when 
$\mathrm{Q}_{\mathrm{NBL}}$ is similar to $\mathrm{Q}_{\mathrm{P} w e l l}[6]$. Then, higher NBL dose implantation should be required for compensate the P-well dose implanted in the drift region.

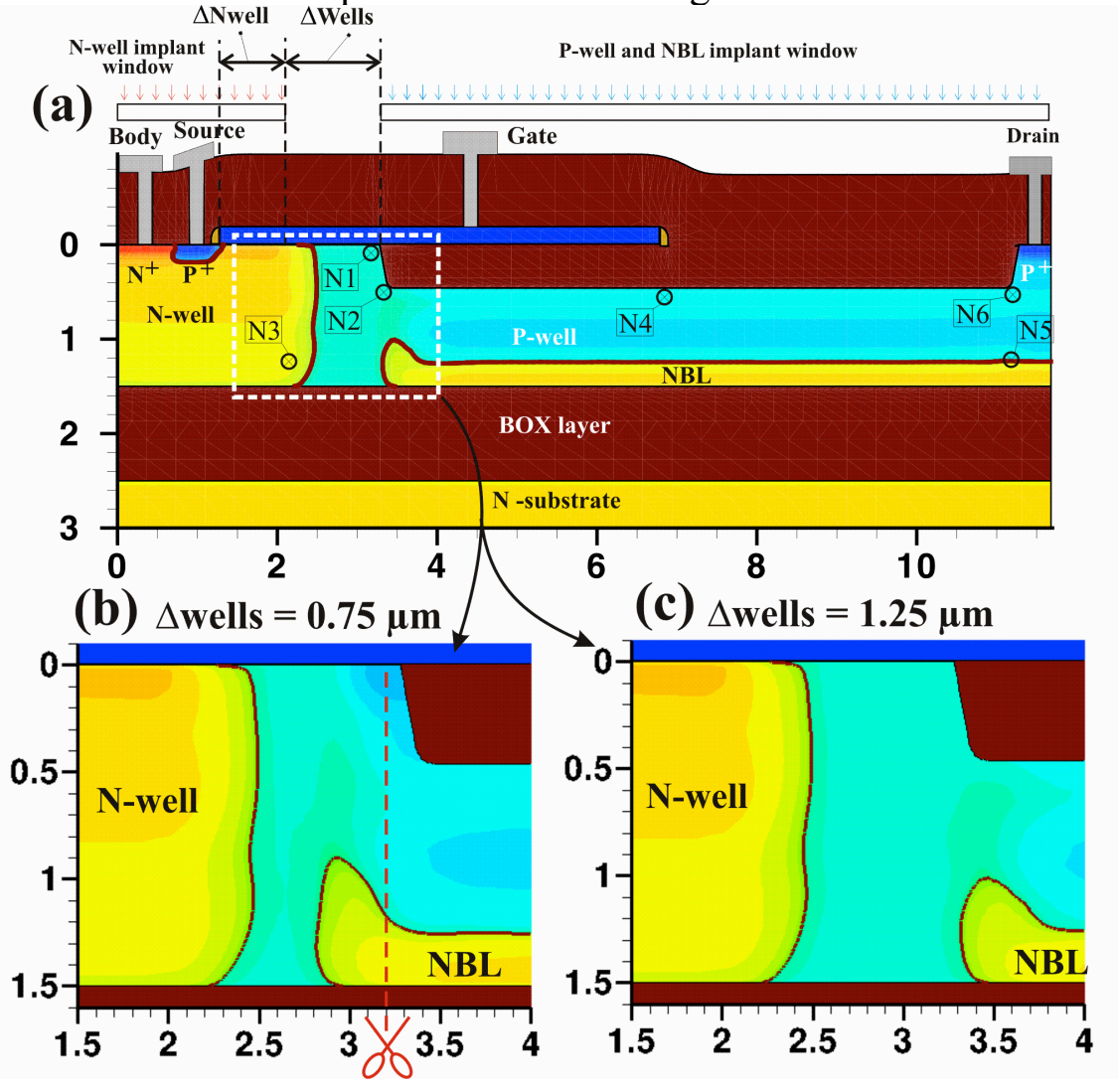

Fig. 2 Simulated cross section of the NBL-LDPMOS structure and the details of the resulted Polygate/STI corner region when a $\Delta$ wells of $0.75 \mu \mathrm{m}$ and $1.25 \mu \mathrm{m}$ is used.

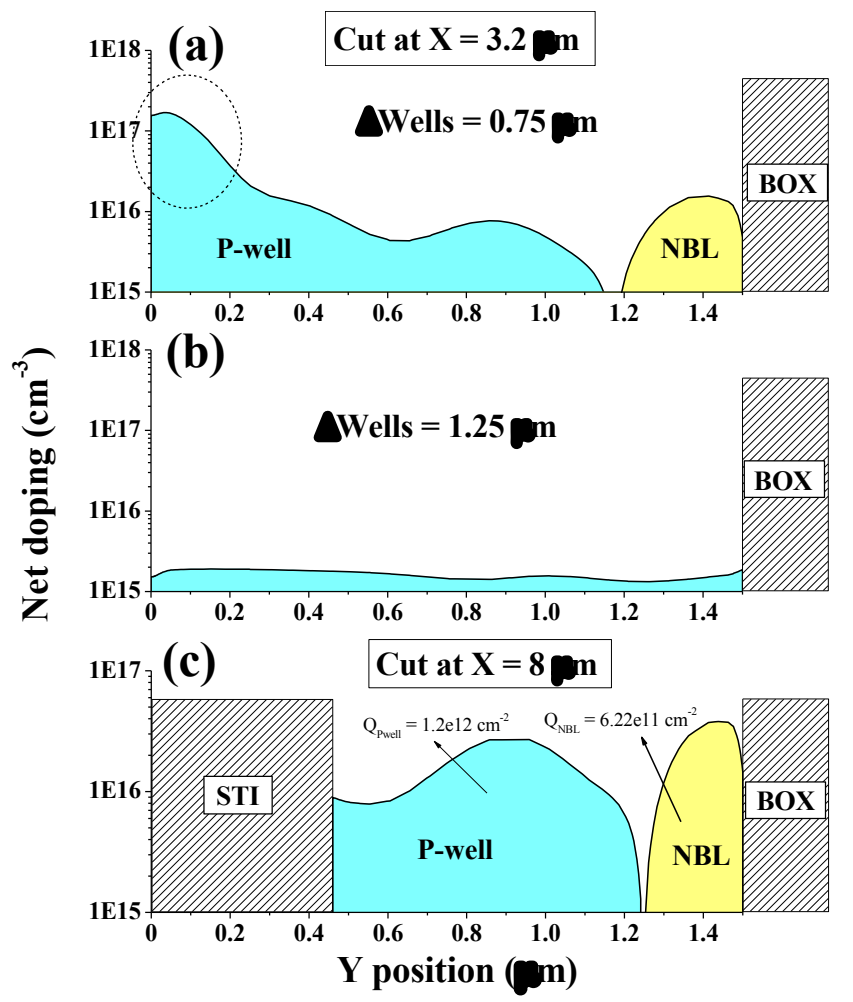


Fig. 3 Net doping profile through the active Silicon active area at Poly-Gate/STI corner region $(X=3.2$ $\mu \mathrm{m})$ for (a) $\Delta W e l l s$ of $0.75 \mu \mathrm{m}$ and (b) for $\Delta W e l l s=1.25 \mu \mathrm{m}$, and in the drift region covered by the $S T I(X$ $=8 \mu \mathrm{m})$.
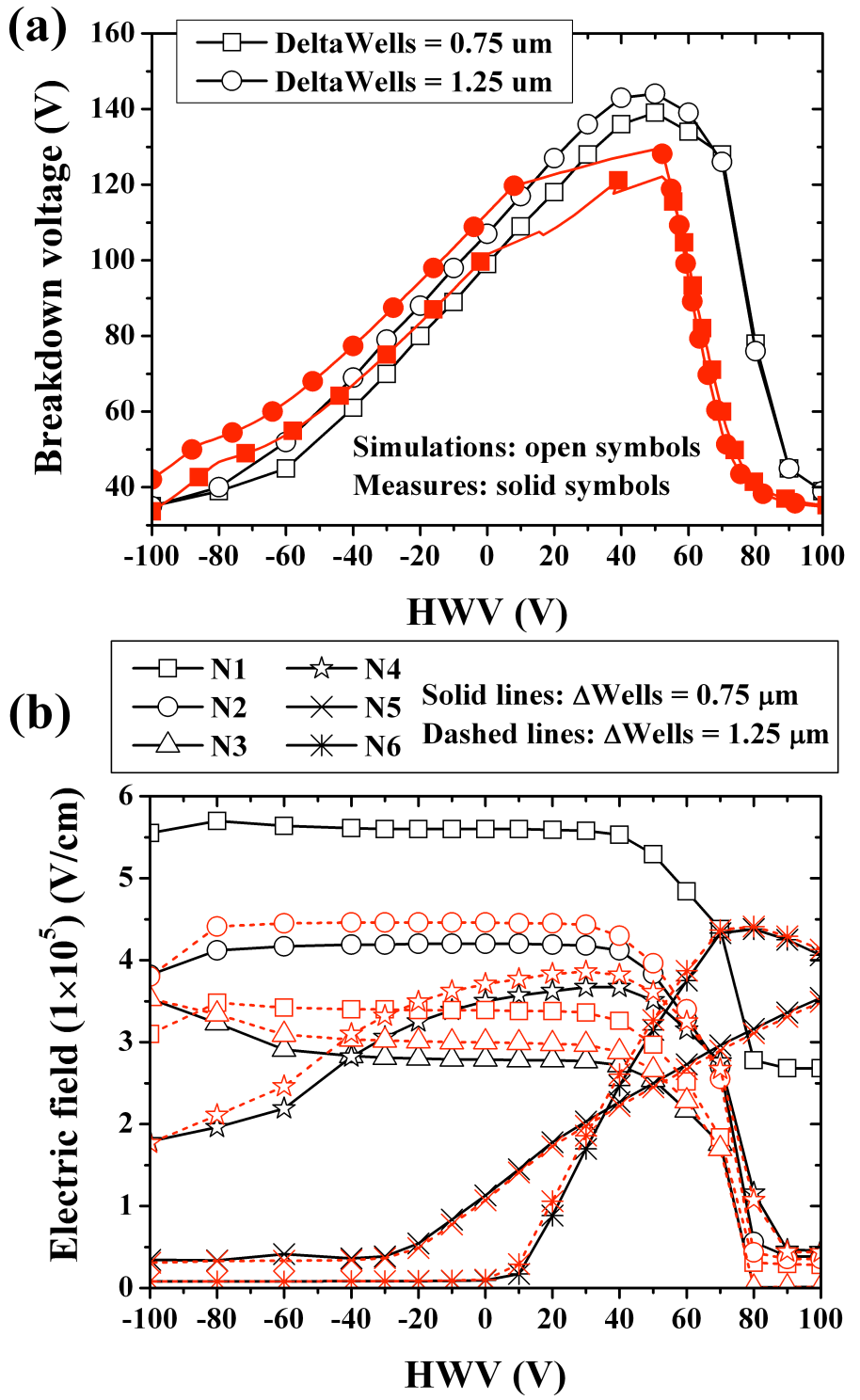

Fig. 4 (a) Comparison between measured and simulated VBR vs $H W V$ and (b) the electric field extracted in the most stressful nodes in NBL-LDPMOS structures with $\triangle W$ ells of $0.75 \mu \mathrm{m}$ and $1.25 \mu \mathrm{m}$.

\section{Device off-state characteristics}

Fig. 4 shows the comparison between measurements and simulations of the breakdown voltage $\left(\mathrm{V}_{\mathrm{BR}}\right)$ evolution as a function of the substrate (handle wafer) voltage (HWV). The reverse biased simulations and measurements at different HWV values are carried out with the Drain electrode grounded and both the Source and Gate electrodes biased with the same voltage. From Fig. $4 a$, it can be observed that the maximum $V_{B R}$ value is obtained for high positive HWV, which clearly indicates that higher Phosphorus dose must be implanted in the NBL layer to compensate the P-well effective dose. The evolution of the electric field in the most stressful nodes illustrated in Fig. 2a is plotted in Fig. $4 \mathrm{~b}$ as a function of HWV. According to this plot, the optimal HWV value leads to the best electric field distribution among the defined nodes. The difference between the structures with different $\Delta$ Wells values is the much higher electric field located at 
node $\mathrm{N} 1$, observed in the case of $\Delta$ Wells of $0.75 \mu \mathrm{m}$, especially at negative HWV values. This harmful electric field is clearly related with the high $\mathrm{BF}_{2}$ concentration in the gate oxide surface close to the STI [8].

\section{Device on-state characteristics}

The comparison of the measured and simulated (non-isothermal) on-state characteristics illustrated in Fig. 4 shows (a) the voltage transfer characteristic and (b) the output characteristics of the NBL-LDPMOS structures. The direct biased simulations and measurements are carried out with the drain and HWV electrodes grounded and both the Source and Gate electrodes biased with the same voltage keeping a $V_{g s}$ of $-3 \mathrm{~V}$. Similar measured and simulated $\mathrm{V}_{\mathrm{TH}}$ values in the range of $-0.3 \mathrm{~V}$ (see Fig. $4 \mathrm{a}$ ) are obtained in both structures. However, in spite of the good fit between measured and simulated output curves achieved for $\Delta$ Wells of $1.25 \mu \mathrm{m}$ (Fig. $4 \mathrm{~b}$ ), high discrepancy is obtained for $\Delta$ Wells of $0.75 \mu \mathrm{m}$ at linear region. As commented before, for $\Delta$ Wells of $0.75 \mu \mathrm{m}$, a certain portion of the P-well implantation mask is not covered by the STI, thus leading to an increment of Phosphorus (NBL queue) and BF2 and Boron concentration close to the STI Source corner. Then, in spite of using a more accurate Monte Carlo implantation simulation, the drift between simulated and measured effective dose implanted due to possible mask misalignments or $\mathrm{Si} / \mathrm{SiO}_{2}$ species segregation will be more noticeable in the case of $\Delta$ Wells of $0.75 \mu \mathrm{m}$. Besides, from output curves results, high $\left|\mathrm{V}_{\mathrm{ds}}\right|$ saturation voltage are obtained in both cases, especially when $\Delta$ Wells of 1.25 $\mu \mathrm{m}$, due to the low boron concentration in the Gate/STI region (see Fig. 3b), which highly increases the drift resistance, and thus the $\mathrm{R}_{\text {on-sp. }}$. Table I shows the final results of $\mathrm{R}_{\mathrm{on}-\mathrm{sp}} / \mathrm{V}_{\mathrm{BR}}$ trade-off obtained in the NBL-LDPMOS experimental structures. 

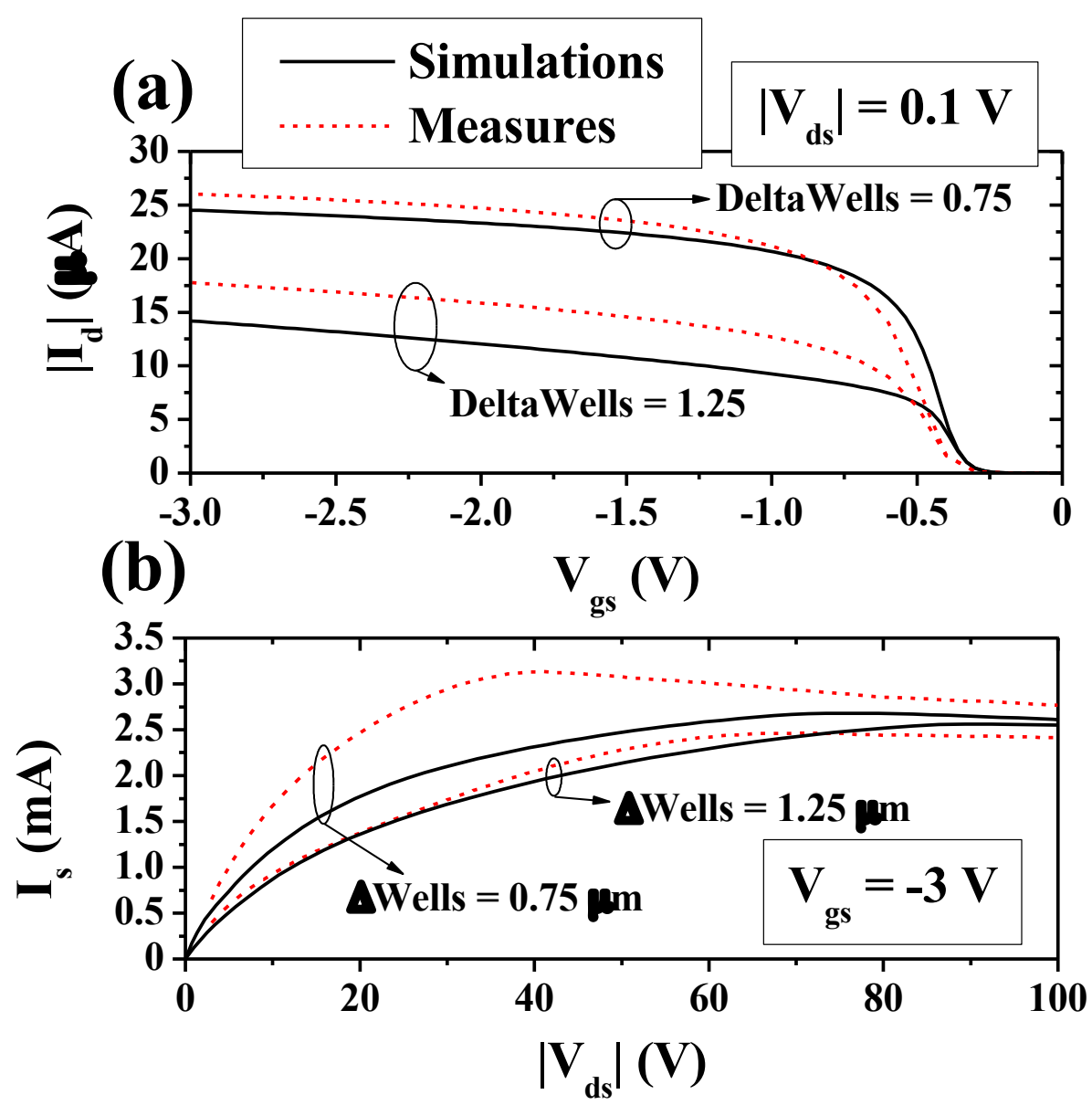

Fig. 5 Measured and simulated device on-state (a) $\left|I_{d}\right|-V_{g s}$ and (b) $I_{s^{-}}\left|V_{d s}\right|$ characteristics in $N B L-$ LDPMOS structures with $\triangle$ Wells of $0.75 \mu \mathrm{m}$ and $1.25 \mu \mathrm{m}$

\begin{tabular}{ccc}
\hline NBL-LDPMOS description & $\mathbf{V}_{\mathbf{B R}}(\mathbf{V})$ & $\mathbf{R}_{\mathbf{\text { on-sp }}}\left(\mathbf{m} \boldsymbol{\mathbf { m } \times \mathbf { c m } ^ { \mathbf { 2 } } )}\right.$ \\
\hline \hline$\Delta \mathrm{Wells}=0.75 \mu \mathrm{m}$ & $122 @ \mathrm{HWV}=52 \mathrm{~V}$ & $\begin{array}{l}14.5 @ \mathrm{~V}_{\mathrm{gs}}=-3 \mathrm{~V} \\
12.4 @ \mathrm{~V}_{\mathrm{gs}}=-10 \mathrm{~V}\end{array}$ \\
$\mathrm{~L}_{\mathrm{LDD}}=8 \mu \mathrm{m}, \mathrm{L}_{\mathrm{STI}}=8 \mu \mathrm{m}$ & \multirow{2}{*}{$130 @ \mathrm{HWV}=50 \mathrm{~V}$} & $\begin{array}{l}22.2 @ \mathrm{~V}_{\mathrm{gs}}=-3 \mathrm{~V} \\
16 @ \mathrm{~V}_{\mathrm{gs}}=-10 \mathrm{~V}\end{array}$ \\
$\begin{array}{c}\Delta \mathrm{Wells}=1.25 \mu \mathrm{m} \\
\mathrm{L}_{\mathrm{LDD}}=8 \mu \mathrm{m}, \mathrm{L}_{\mathrm{STI}}=8 \mu \mathrm{m}\end{array}$ &
\end{tabular}

Table 1 NBL-PLDMOS $R_{\text {on-sp }} / V_{B R}$ characteristics.

\section{NBL-LDPMOS structure optimization}

In the NBL-LDPMOS structures from previous sections, the technological criteria used in their fabrication is linked with the CMOS technology, thus leading to some restrictions. Particularly, those concerning the multi-implantation sequences that define the N-well and the P-well/NBL regions. In order to improve the voltage capability of the NBL-LDPMOS transistors, better RESURF effectiveness must be achieved by providing similar $\mathrm{Q}_{\mathrm{P}-\mathrm{well}}$ and $\mathrm{Q}_{\mathrm{NBL}}$ in the drift region [6]. As a consequence, a new multi-implantation sequence of Boron and Phosphorus is defined in the drift region. Besides, the N-well multi-implantation sequence is also modified with the purpose to obtain a more uniformed doping profile through the active SOI Silicon layer.

Some other structure modifications are taken into account: Different mask definition parameters such as $\Delta \mathrm{N}$-well of $0.25 \mu \mathrm{m}, \Delta \mathrm{Wells}$ values from $0.75 \mu \mathrm{m}$ to $1.75 \mu \mathrm{m}$ and a 
$\Delta$ LPoly of $1.5 \mu \mathrm{m}$. Different thicknesses such as a $\mathrm{T}_{\mathrm{SOI}}$ of $1.6 \mu \mathrm{m}$, a $\mathrm{T}_{\mathrm{STI}}$ of $0.4 \mu \mathrm{m}$, and a $\mathrm{T}_{\mathrm{ox}}$ of $20 \mathrm{~nm}$ which leads to a $\mathrm{V}_{\mathrm{TH}}$ of $-1.5 \mathrm{~V}$. And finally different length definitions such as slightly shorter $\mathrm{L}_{\mathrm{LDD}}$ of $7 \mu \mathrm{m}$ and different $\mathrm{L}_{\mathrm{STI}}$ partially $\left(\mathrm{L}_{\mathrm{STI}}\right.$ of 2 and 4 ) and totally covering the LDD ( $\mathrm{L}_{\mathrm{STI}}$ of $7 \mu \mathrm{m}$ ) have been also considered. The STI partially covering the LDD is defined with the purpose of not only improving the electric field distribution at breakdown and so the $R_{\mathrm{on}-\mathrm{sp}} / V_{\mathrm{BR}}$ trade-off [9], but also improving the device safe-operating-area (SOA) [2].

The proposed new NBL-LDPMOS structure with the STI partially covering $\left(\mathrm{L}_{\mathrm{STI}}=4\right.$ $\mu \mathrm{m})$ is shown in Fig. 6a, while a detail of the new P-well/NBL drift doping profile is illustrated in Fig. 6b. In this case the NBL layer connects with the N-well diffusion thanks to the low $\Delta \mathrm{N}$-well and the $\Delta \mathrm{Wells}$ of $0.75 \mu \mathrm{m}$ used. For higher $\Delta$ Wells values, no NBL/N-well overlapping is achieved.

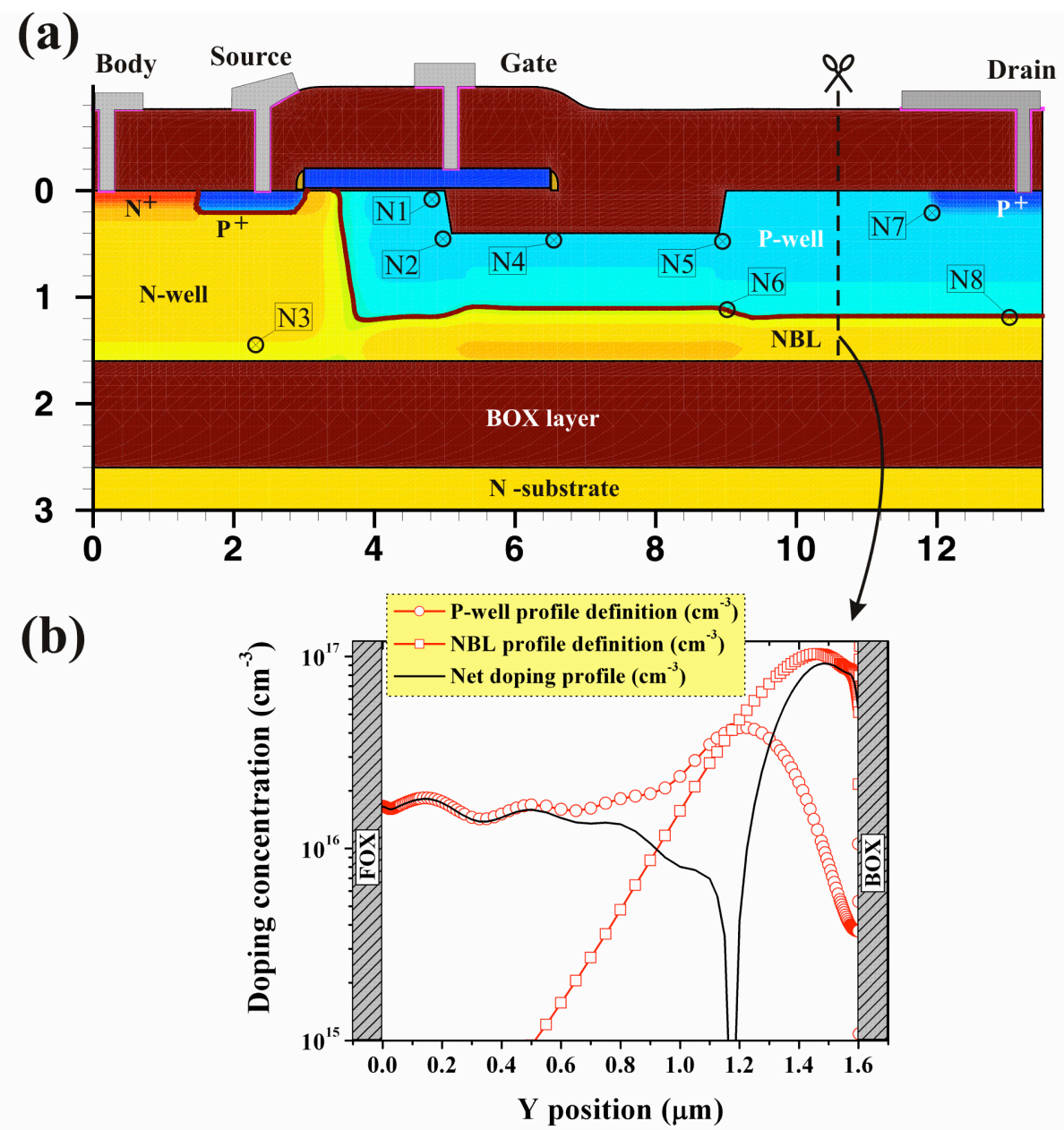

Fig. 6 (a) Schematic cross-section of the proposed new NBL-LDPMOS transistor and (b) the obtained doping profile throughout the SOI layer. Parameters used in this structure: $\Delta N$-well of $0.25 \mu m, \Delta W e l l s$ of $0.75 \mu \mathrm{m}, L_{S T I}$ of $4 \mu \mathrm{m}$ and $\triangle L$ Poly of $1.5 \mu \mathrm{m}$.

$R_{\text {on-sp }} / V_{B R}$ trade-off

Previous optimization of the NBL (Phosphorus) and P-well (Boron) implantation dose has been performed to obtain the best performance in terms of $\mathrm{R}_{\mathrm{on}-\mathrm{sp}} / \mathrm{V}_{\mathrm{BR}}$ trade-off for different $\mathrm{L}_{\mathrm{STI}}$ values. Fig. $6 \mathrm{~b}$ shows the doping profile in the LDD region not covered by the STI where the different doping peaks corresponds to a different implantation energy. However, the low energy Boron implantation peak will be located inside the STI block 
in the region covered by the STI [9]. As a consequence, the longer the $\mathrm{L}_{\mathrm{STI}}$, the higher the P-well optimal implantation dose. Fig. 7 shows the simulation results of $R_{o n-s p} / V_{B R}$ trade-off as a function of P-well implantation dose increment in the new NBLPLUDMOS structures with different $\mathrm{L}_{\mathrm{STI}}$ values. Although the maximum $\mathrm{V}_{\mathrm{BR}}$ value is achieved for $\mathrm{L}_{\mathrm{STI}}$ values of $2 \mu \mathrm{m}$, optimal $\mathrm{R}_{\mathrm{on}-\mathrm{sp}} / \mathrm{V}_{\mathrm{BR}}$ trade-off is obtained in $\mathrm{L}_{\mathrm{STI}}$ of 4 $\mu \mathrm{m}$ structures since high $\mathrm{V}_{\mathrm{BR}}$ values is mantained for a wide $\mathrm{P}$-well implantation dose. Moreover, the voltage capability is highly reduced when the STI completely covers the LDD region. Table 2 resume the final optimal results obtained in this plot.

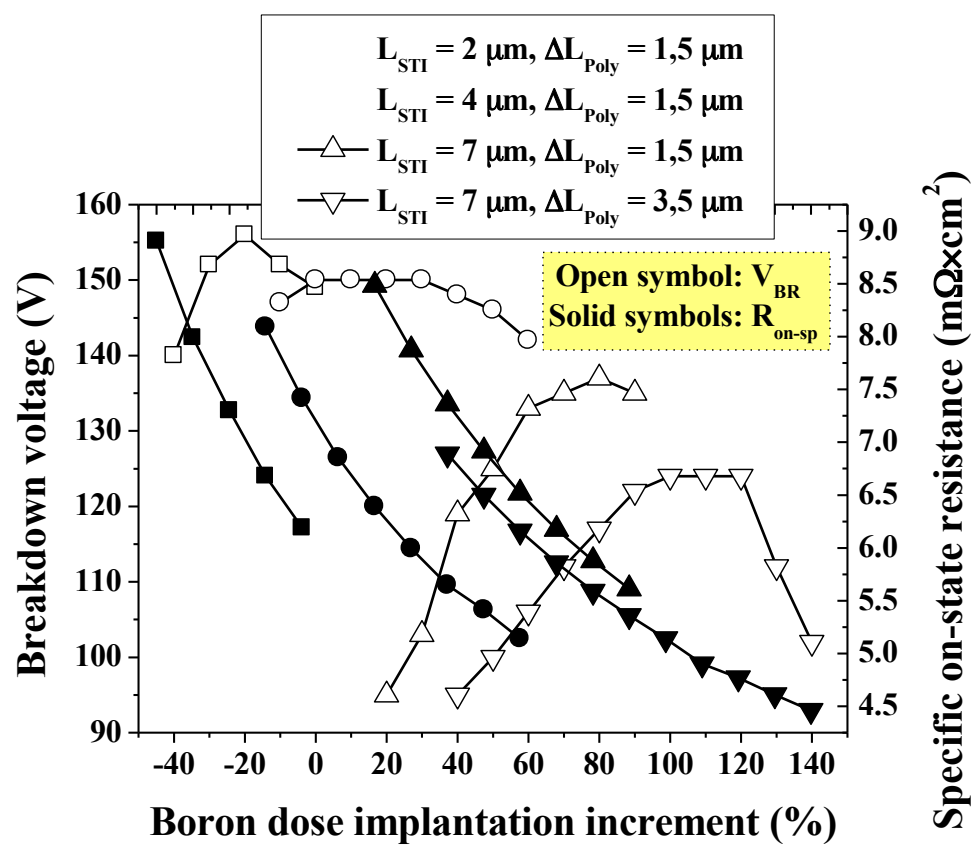

Fig. $7 R_{\text {on-sp }} / V_{B R}$ trade-off as a function of P-well dose percentage increment in the new NBL-LDPMOS structures with different $L_{S T I}$ and $\Delta L_{\text {poly }}$ definitions. The Ron-sp simulations are performed with $V_{g s}=-10 \mathrm{~V}$. Parameters used in this structure: $\Delta \mathrm{N}$-well of $0.25 \mu \mathrm{m}$, $\Delta$ Wells of $0.75 \mu \mathrm{m}$.

\section{$V B R$ vs $H W V$}

The simulation evolution of the $\mathrm{V}_{\mathrm{BR}}$ VS HWV of the best NBL-LDPMOS structures in terms of $\mathrm{R}_{\mathrm{on}-\mathrm{sp}} / \mathrm{V}_{\mathrm{BR}}$ trade-off from Fig. 7 have been compared in Fig. 8a. As observed in this figure, in spite of reducing the $L_{L D D}$, slightly higher $V_{B R}$ can be reached in the proposed structure. Moreover, the highest $V_{B R}$ peak and the best $V_{B R}$ evolution vs HWV are obtained for $\mathrm{L}_{\mathrm{STI}}$ of $2 \mu \mathrm{m}$ and $4 \mu \mathrm{m}$, respectively. In Fig. 8b, the NBL-LDPMOS structure with $\mathrm{L}_{\mathrm{STI}}$ of $4 \mu \mathrm{m}$ is further analysed by means of the electric field evolution vs HWV in the most stressful nodes illustrated in Fig. 6a. A well distributed electric field in all nodes can be observed at a HWV range between $0 \mathrm{~V}$ and $30 \mathrm{~V}$, where the $\mathrm{V}_{\mathrm{BR}}$ maximum plateau is reached. At negative $\mathrm{HWV}$, the NBL layer is easily depleted by the field-effect action of the substrate, thus avoiding the P-well depletion in the drift region. Besides, the $\mathrm{N}$-well is vertically and laterally depleted by the substrate and the P-well layer. As a consequence, breakdown will be located at the gate/STI corner region (nodes N1 and N3) as observed in Fig. 8b. The same way than in fabricated NBLLDPMOS transistors with $\Delta$ wells of $0.75 \mu \mathrm{m}$, high electric field also appears in N1 at negative HWV in spite of avoiding the BF2 surface implantation. Although the Polygate acts as a field plate by smoothing the surface electric field, the low $\Delta \mathrm{N}$-well of 0.25 
$\mu \mathrm{m}$ used in these simulations has increased the P-well implantation window overhanging the Gate region. This fact leads to an increment of Boron concentration which is difficult to deplete specially at negative HWV values. Positive HWV leads to an opposite situation where P-well layer in the drift region easely depletes thanks to the combined action of the substrate field-effect and the NBL layer. Therefore, the breakdown region is shifted to the STI Drain corner, especially at nodes N8 (see Fig. $8 b)$.
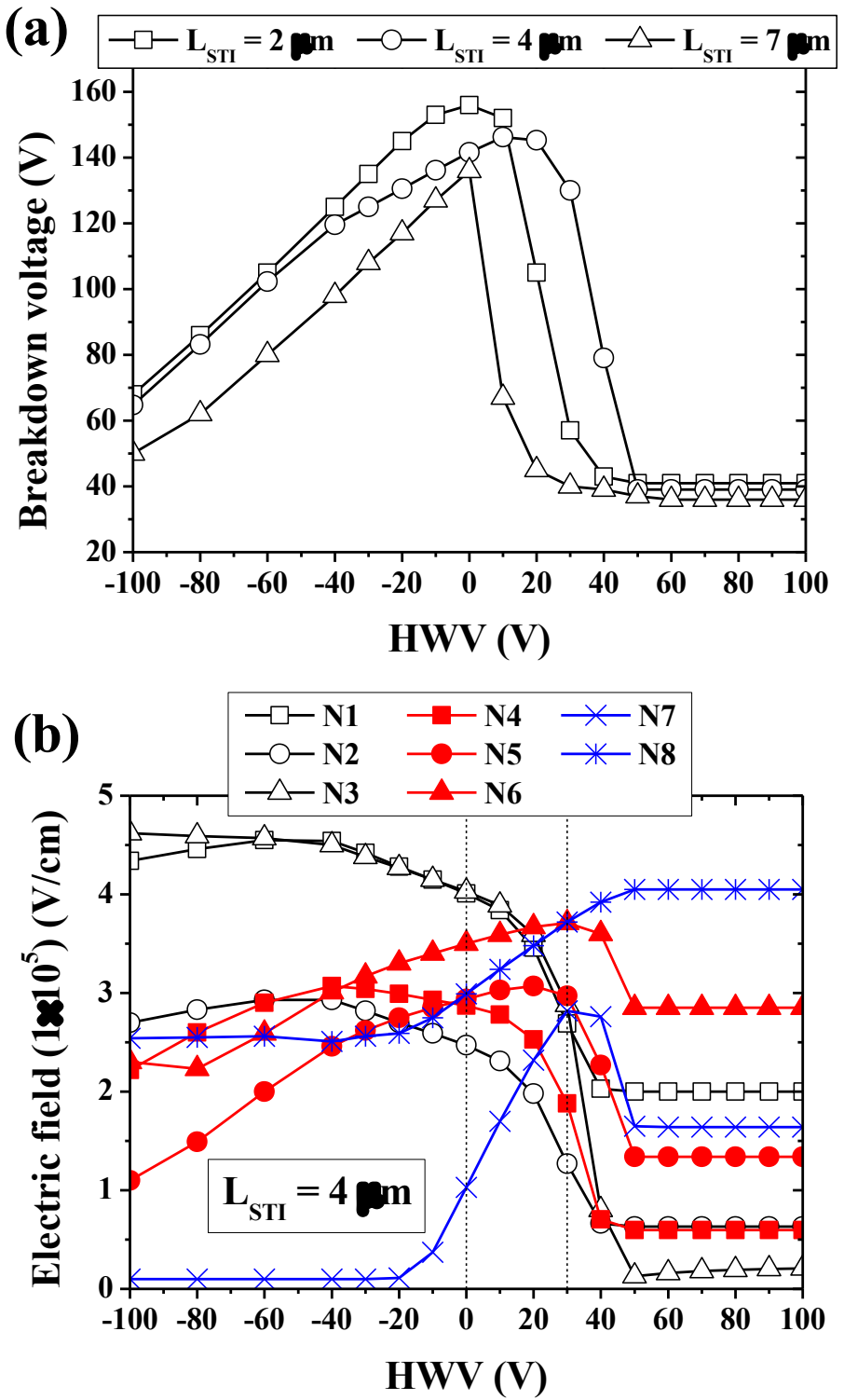

Fig. 8 (a) Simulated VBR vs $H W V$ and (b) the electric field extracted in the most stressful nodes in the new NBL-LDPMOS structure with different $L_{S T I}$ values. Parameters used in this structure: $\Delta N$-well of $0.25 \mu \mathrm{m}, \Delta$ Wells of $0.75 \mu \mathrm{m}$, LLPoly of $1.5 \mu \mathrm{m}$. 


\begin{tabular}{ccc}
\hline NBL-LDPMOS description & $\mathbf{V}_{\text {BR }}(\mathbf{V})$ & $\mathbf{R}_{\mathbf{0 n}-\mathrm{sp}}\left(\mathbf{m} \boldsymbol{\Omega} \times \mathbf{c m}^{2}\right)$ \\
\hline \hline$\Delta \mathrm{Welll}=0.75 \mu \mathrm{m}$ & \multirow{2}{*}{$156 @ \mathrm{HWV}=0 \mathrm{~V}$} & $9.7 @ \mathrm{~V}_{\mathrm{gs}}=-3 \mathrm{~V}$ \\
$\mathrm{~L}_{\mathrm{LDD}}=7 \mu \mathrm{m}, \mathrm{L}_{\mathrm{STI}}=2 \mu \mathrm{m}$ & $7.73 @ \mathrm{~V}_{\mathrm{gs}}=-10 \mathrm{~V}$ \\
\hline$\Delta \mathrm{Wells}=0.75 \mu \mathrm{m}$ & \multirow{2}{*}{$146 @ \mathrm{HWV}=10 \mathrm{~V}$} & $7.8 @ \mathrm{~V}_{\mathrm{gs}}=-3 \mathrm{~V}$ \\
$\mathrm{~L}_{\mathrm{LDD}}=7 \mu \mathrm{m}, \mathrm{L}_{\mathrm{STI}}=4 \mu \mathrm{m}$ & & $6.32 @ \mathrm{~V}_{\mathrm{gs}}=-10 \mathrm{~V}$ \\
\hline$\Delta \mathrm{Wells}=0.75 \mu \mathrm{m}$ & \multirow{2}{*}{$136 @ \mathrm{HWV}=0$} & $7.33 @ \mathrm{~V}_{\mathrm{gs}}=-3 \mathrm{~V}$ \\
$\mathrm{~L}_{\mathrm{LDD}}=7 \mu \mathrm{m}, \mathrm{L}_{\mathrm{STI}}=7 \mu \mathrm{m}$ & $5.97 @ \mathrm{~V} \mathrm{gs}=-10 \mathrm{~V}$ \\
\hline
\end{tabular}

Table 2 new optimized NBL-PLDMOS $R_{\text {on-sp }} / V_{B R}$ simulated characteristics.

\section{SOA boundary}

In this section, non-isothermal simulations of the output characteristics are performed to define the SOA boundary of the fabricated NBL-LDPMOS transitor (see Fig. 2) and the proposed new NBL-LDPMOS structure with $\mathrm{L}_{\text {STI }}$ of $4 \mu \mathrm{m}$ (see Fig. 6). The same thermal resistances configuration extracted from simulations in Fig. 5 are used in this study. Hence, the simulated Drain voltage where the snap-back occurs is plotted at different applied effective $\left(\mathrm{V}_{\mathrm{gs}}-\mathrm{V}_{\mathrm{TH}}\right)$ Gate voltages in Fig. 9. As a first glance, much better SOA boundary conditions can be obtained in the new optimal NBL-LDPMOS structure, especially at high Gate voltage values. On the other hand, the $\Delta$ Wells parameter increment has almost no repercussion in the voltage operation limit in both structures, as seen in Fig. 9. The high differences between both structures at high $\mathrm{V}_{\mathrm{gs}}$ values is attributed not only due to better optimal NBL/P-well layer but also to the higher Phosphorus effective concentration in the $\mathrm{N}$-well layer $\left(\mathrm{Q}_{\mathrm{N} \text {-well }}\right)$ of the optimized NBL-LDPMOS structure which reduces the activation of parasitic bipolar transistor [10].

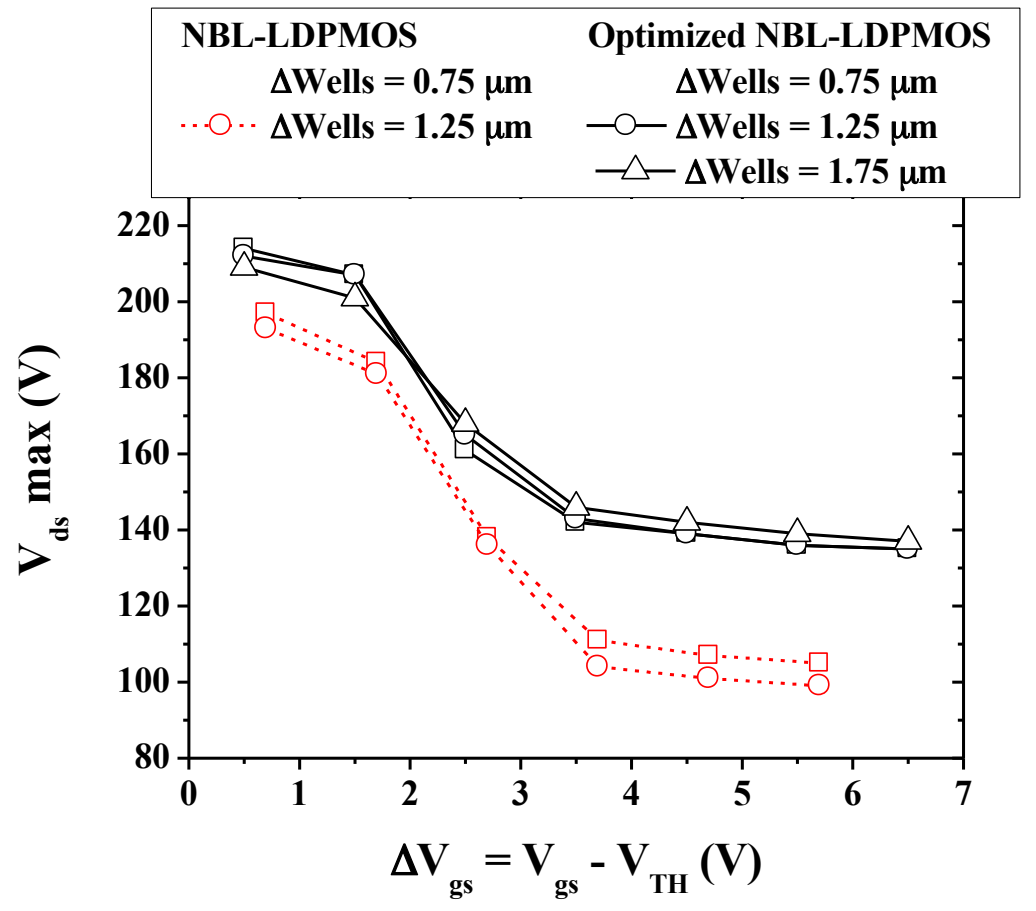

Fig. 9 SOA boundary comparison between fabricated NBL-LDPMOS transistors and proposed new NBLLDPMOS structures considering differnt $\triangle$ Wells values. 


\section{Conclusions}

The low RESURF effectiveness found in conventional P-channel LDMOS transistors requires the search of better optimal drift region design configurations such as the proposed LDPMOS with a NBL layer placed deep inside the SOI Silicon region. A significant improvement of the static performances can be achieved with the NBLLDPMOS structure which assures competitive performances for switching applications. However, the technological process linked with the CMOS technology leads to some restrictions, especially those concerning the multi-implantation sequences that define the $\mathrm{N}$-well and the P-well/NBL regions. Some design modification has been added in the structure to further optimize the performance by means of TCAD technological simulations, e.g. optimal NBL/P-well layers definition by changing the drift and body implantation sequence or definition of an STI partially covering the drift region.

\section{Acknowledgment}

This work was supported by MEDEA + (project 2T205 SPOT-2), and partially supported by CYCIT.

\section{References}

[1] Matsumoto S, Kim I-J, Sakai T, Fukumitsu T, Yachi T. Switching characteristics of a thin film-SOI power MOSFET. Jpn J Appl Phys 1995;34:817 - 21.

[2] Cortés I, Toulon G, Morancho F, Urresti J, Perpinya X, Villard B. Analysis and optimization of Safe-Operating-Area of LUDMOS transistors on $0.18 \mu \mathrm{m}$ SOI CMOS technology. Semicond. Sci Technol. 2010;25:045013.

[3] Imam M, Hossain Z, Quddus M, Adams J, Hoggat C, Ishiguro T, Nair R. Design and optimization of double-RESURF high-voltage lateral devices for manufacturable process. IEEE Trans Electron Dev. 2003;50(7):1697 - 70.

[4] Kawai F, Onishi T, Kamiya T, Ishimabushi H, Eguchi H, Nakahama K, Aoki H, Hamada K. Multi-voltage SOI-BiCDMOS for $14 \mathrm{~V} \& 42 \mathrm{~V}$ automotive applications. Proc. ISPSD 2004 pp. 165 - 68.

[5] Nitta T, Yanagi S, Miyajima T, Furuya K, Otsu Y, Onoda H, Hatasako K. Wide voltage Power Device implementation in $0.25 \mu \mathrm{m}$ SOI BiC-DMOS. Proc. ISPSD 2006, pp. $431-35$.

[6] Cortés I, Toulon G, Morancho F, Hugonnard-Bruyere E, Villard B, Toren WJ. Design and optimization of different P-channel LUDMOS architectures on a 0.18 $\mu \mathrm{m}$ SOI-CMOS technology. Semicond. Sci Technol. 2011;26:075018.

[7] Sentaurus TCAD tools suite. Synopsys 2010.

[8] Toulon G, Cortés I, Morancho F, Hugonnard-Bruyère E, Villard B, Toren WJ.

Design and optimization of high voltage LDMOS transistors on $0.18 \mu \mathrm{m}$ SOI CMOS technology. Solid-State Electron. 2011. In Press.

[9] Cortés I, Fernández-Martínez P, Flores D, Hidalgo S, Rebollo J. Static and dynamic electrical performances of STI thin-SOI power LDMOS transistors. Semicond. Sci Technol. 2008;23(9):095024

[10] Lin J, Hower PL. Two-carrier current saturation in a lateral DMOS. In Proc ISPSD 2006, pp. 1 - 4. 
